\title{
Effectiveness of a Seed Plate Assay for Evaluating Charcoal Rot Resistance in Soybean and the Relationship to Field Performance
}

\author{
Marcos P. da Silva, ${ }^{1}$ Andy Pereira, ${ }^{1}$ John C. Rupe, ${ }^{2, \dagger}$ Burt H. Bluhm, ${ }^{2}$ Edward E. Gbur, ${ }^{3}$ Lisa Wood, ${ }^{1}$ Leandro A. Mozzoni, ${ }^{1}$ \\ and Pengyin Chen ${ }^{4}$ \\ ${ }^{1}$ Department of Crop, Soil, and Environmental Sciences, University of Arkansas, Fayetteville, AR 72701 \\ 2 Department of Plant Pathology, University of Arkansas, Fayetteville, AR 72701 \\ ${ }^{3}$ Agriculture Statistics Lab, University of Arkansas, Fayetteville, AR 72701 \\ ${ }^{4}$ Fisher Delta Research Center, University of Missouri, Portageville, MO 63873
}

\begin{abstract}
Charcoal rot of soybean, caused by Macrophomina phaseolina, is a disease of economic significance in the United States. Although there are soybean cultivars with moderate resistance, identifying and quantifying resistance is challenging. Existing assays are time consuming, and results are often highly variable. The objectives of this research were to (i) create a reproducible seed plate assay (SPA) for charcoal rot resistance and (ii) correlate field-based disease assessments with SPA results on diverse soybean accessions. To develop the SPA, surface-disinfected seeds from eight soybean genotypes (representing three susceptible and five resistant cultivars) were placed on water agar plates inoculated with M. phaseolina. After incubation at room temperature in darkness for 7 days, percent germination was determined for each cultivar relative to the germination on noninoculated plates. Results from SPA were in general agreement with

analyzed for correlation with field disease assessments from Stuttgart, AR, from 2011 to 2014 and from Rohwer, AR, in 2011 and 2012 SPA consistently categorized soybean genotype resistance compared with field disease assessment averages, and results were consistent with previously published resistance determinations. SPA was significantly correlated with percent height of internal stem discoloration (PHSD) at Stuttgart from 2011 to 2013 and in 2012 at Rohwer, with root and stem severity (RSS) at Rohwer in 2012, and with tap root colonization (CFU) at Stuttgart in 2012. SPA was significantly correlated to yield at Stuttgart in 2011, 2013, and 2014, and in 2011 and 2012 at Rohwer. Yield was not correlated to RSS, PHSD, or CFU at either location or in any year. Therefore, SPA is a reproducible and rapid assay for charcoal rot resistance in soybean and is significantly associated to field performance.
\end{abstract} published responses. None of the soybean genotypes showed complete resistance to M. phaseolina. For the second objective, charcoal rot resistance in 18 soybean accessions was assayed with SPA, and results were
Keywords: Macrophomina phaseolina, soybean, disease management, cultivar resistance
Macrophomina phaseolina (Tassi) Goid. (Goidanish 1947) is a causative agent of charcoal rot in more than 500 plant species around the world, including economically important crops such as soybean (Glycine max [L.] Merr.), corn (Zea mays L.), sorghum (Sorghum bicolor [L.] Moench), and fruits, legumes, and cotton (Gossypium hirsutum L.) (Baird and Brock 1999; Dhingra and Sinclair 1978; Su et al. 2001; Wyllie 1988). In the United States, charcoal rot in soybean was first observed in east Texas (Young 1949) and has been reported throughout the country since then.

M. phaseolina can infect soybeans from seedlings to mature plants, although infections remain latent until plants become stressed (Bristow and Wyllie 1986; Collins et al. 1991; Short et al. 1978). Abiotic stresses, such as drought and heat, play an important role in the weakening of plant defenses and enhance susceptibility to charcoal rot (Grodzki et al. 2004; Sandermann 2004). Symptoms of charcoal rot mainly appear during hot and dry conditions and are more prevalent during reproductive stages of soybean development. Symptoms are variable and can include stunted growth, leaf chlorosis, early maturation, and incomplete pod filling (Mengistu et al. 2015). However, charcoal rot is generally associated with rapid

${ }^{\dagger}$ Corresponding author: J. C. Rupe; jrupe@uark.edu

Funding: This effort was funded in part by a grant from the United Soybean Board project number 1247 "Charcoal Rot: Confirmation of Resistance in Adapted and Exotic Sources of Resistance." The research was also supported by the University of Arkansas Experiment Station and U.S. Department of Agriculture.

The author(s) declare no conflict of interest.

Accepted for publication 28 February 2019.

() 2019 The American Phytopathological Society plant death and the appearance of small, black microsclerotia on and in the tap root. Colonization can extend up the stem and may reach the top of the plant. Seed infection can also occur.

Control of charcoal rot is usually through cultural methods that reduce drought stress or reduce soil inoculum, such as staggered planting dates, rotation with nonhost crops, reduced plant densities, and irrigation (Bowen and Schapaugh 1989; Francl et al. 1988; Wrather et al. 2007). Soil fumigation with methyl bromide, chloropicrin, or sodium methyldithiocarbamate can reduce populations of M. phaseolina microsclerotia in the soil but did not prevent charcoal rot when environmental conditions favored the disease (Kittle and Gray 1982; Pearson et al. 1984; Watanabe et al. 1970). None of these approaches offers a high level of disease control or is always practical in soybean production. An alternative control measure is the use of genetic resistance.

Generally, soybean resistance to charcoal rot is assessed at the end of the season by determining the level of root colonization by the fungus. This is done by air drying roots, grinding them to a fine powder, and plating this powder on a selective medium to determine the number of colony-forming units of $M$. phaseolina per gram of root (CFU). Short et al. (1978) reported that 'Amsoy 71' had much higher levels of colonization than 'A-100', but only when roots were sampled at the end of the season. Colonization levels between the cultivars were similar when roots were sampled earlier. Smith and Carvil (1997) refined the method and assayed 24 cultivars over 2 years. Consistent reactions occurred between years for the most susceptible and the most resistant lines, but for a number of lines with intermediate reaction, there was considerable variability in colonization between years. To reduce year-to-year variability, Mengistu et al. (2007) developed a colony-forming unit index (CFUI) derived by dividing the CFU of a cultivar by the CFU value of a standard susceptible cultivar. Comparing 24 soybean cultivars over 2 years, they reported clear and consistent differences in CFUI between lines. 
Grinding and plating roots to determine CFUs is a long and highly labor-intensive process. Mengistu et al. (2007) proposed two methods to visually assess root colonization: the root and stem severity index (RSS) involved sampling roots at the end of the season, for which the roots were dried and split, and the amount of internal root discoloration was rated on a 1 to 5 scale. They also measured the total stem length and the length of the stem with visible microsclerotia to determine the percent height of internal stem discoloration (PHSD). Both of these methods could separate cultivar reactions to M. phaseolina, but there was more year-to-year variability with these methods than with CFUI. RSS was used to characterize the response of 628 soybean accessions (Mengistu et al. 2013).

End-of-season assessment of colonization is problematic. The level of colonization can vary greatly between years and locations, and the assessment measures, even RSS and PHSD, are labor intensive (Mengistu et al. 2007). Another problem is that these assessments are occurring at a time of rapid colonization of the root and stem by $M$. phaseolina. Low levels of root infection occur throughout the season, but colonization increases rapidly and microsclerotia form once the plant begins to senesce (Kendig et al. 2000; Mengistu et al. 2007; Short et al. 1978). Because sampling occurred during this period of rapid colonization, the moment in time when a plant is sampled can significantly affect the level of colonization and its relative ranking compared with other cultivars.

Twizeyimana et al. (2012) developed a cut-stem greenhouse assay for charcoal rot. In this assay, stems of 6-week-old plants were cut off $25 \mathrm{~mm}$ above the unifoliate node. The cut surface was inoculated with mycelium of $M$. phaseolina and the length of the resulting necrosis measured every 3 days for up to 2 weeks. Cultivar reactions with this method were similar to those of field assessments. Although faster than field tests, the cut-stem assay still takes up to 8 weeks to evaluate cultivars. A potentially faster and less labor-intensive assay is the seed plate assay (SPA). This assay was first developed to identify resistance to Pythium spp. in alfalfa (Altier and Thies 1995). It has been used to screen for pathogenicity of isolates of Pythium spp. (Broders et al. 2007), for resistance in soybean to $P$. aphanidermatum (Urrea et al. 2017), and to evaluate fungicide seed treatment on corn for control of Fusarium spp. (Munkvold and O'Mara 2002). The technique begins by growing the fungus on an agar medium in Petri dishes until the plate is colonized. Ten surface-disinfested seeds are then placed on the agar, and the plates incubated for a week in the dark, after which the germinated seeds are counted. The SPA has not been used to test cultivar resistance to charcoal rot.

The objectives of this research were to (i) create a reproducible SPA for charcoal rot resistance and (ii) correlate field-based disease assessments with SPA results on diverse soybean accessions.

\section{Materials and Methods}

SPA. An isolate of M. phaseolina collected from soybean roots in Conway, AR, in 2003 and stored at $-80^{\circ} \mathrm{C}$ was grown on potato dextrose agar (PDA, BD Difco, Fisher Scientific) for 5 days at room temperature. Plugs from the edge of the actively growing colony were transferred to the center of $2 \%$ water agar in a $9.0-\mathrm{cm}$-diameter Petri dish. The surface of the agar was covered with $2 \mathrm{~g}$ of sterile vermiculite (medium vermiculite, Sun Gro, Bellevue, WA) (Avanzato 2011). Seeds were surface disinfested by immersing in $70 \%$ ethanol for $3 \mathrm{~min}$ and air drying on an autoclaved paper towel. Ten soybean seeds were then evenly placed across the surface of each plate. Plates were covered with aluminum foil to exclude light and incubated at room temperature $\left(22^{\circ} \mathrm{C}\right)$. After 7 days, the number of germinated seeds was determined. Seeds were considered germinated if the radicle was $>1 \mathrm{~cm}$ long and was not visibly colonized by the pathogen (Broders et al. 2007). For each line, one control plate was not inoculated with $M$. phaseolina but was otherwise treated the same as the five inoculated plates.

SPA eight-cultivar experiment. The reaction to M. phaseolina of eight soybean cultivars with reported reactions to charcoal rot were compared using an SPA. The cultivars were LS94-3207, LS98-0358, and Pharaoh, susceptible to charcoal rot, and DT97-4290, DT987553, DT99-16864, DT99-17554, and DT99-17483, moderately resistant to charcoal rot (Mengistu et al. 2007; Twizeyimana et al. 2012). The tests were conducted in a completely randomized design with five replications. The experiment was conducted twice.

Data for each experiment were analyzed separately owing to the variable effects of $M$. phaseolina infestation between the experiments. Analysis of variance (ANOVA) was performed on the germination proportions using a general linear mixed model (PROC GLIMMIX, SAS version 9.4, SAS Institute, Cary, NC) and assuming a binomial distribution.

Comparison of SPA with field tests. The responses of 19 cultivars to charcoal rot were compared with SPA as previously described. The reactions of some of these cultivars have been reported. These cultivars were Hutcheson, susceptible (Wrather et al. 2008); Spenser, susceptible (Twizeyimana et al. 2012); Pharaoh, susceptible (Mengistu et al. 2007, 2011; Pawlowski et al. 2015); LS98-0358, susceptible (Doubledee et al. 2018; Mengistu et al. 2007, 2011); R01581F, susceptible (Doubledee et al. 2018) and moderately susceptible to moderately resistant (Mengistu et al. 2011); DT97-4290, moderately susceptible (Mengistu et al. 2013), moderately resistant (Mengistu et al. 2011), susceptible to moderately resistant (Cross et al. 2012), and moderately susceptible to moderately resistant (Pawlowski et al. 2015; Twizeyimana et al. 2012); and DK4866, susceptible to moderately resistant (Mengistu et al. 2011). The field responses of 18 of these cultivars were compared at the Southeast Research and Extension Center in Rohwer, AR, and the Rice Research and Extension Center in Stuttgart, AR, respectively. Soil types were Crowley silt loam in Stuttgart and Sharkey silty clay in Rohwer. Each cultivar was planted at a seeding rate of $400,000 \mathrm{seed} / \mathrm{ha}$ in four-row plots, $6.09 \mathrm{~m}$ long, with a $0.75-\mathrm{m}$ row spacing at Stuttgart or a $0.95-\mathrm{m}$ row spacing at Rohwer. To ensure even distribution of inoculum, plots were inoculated with an isolate of $M$. phaseolina collected from soybean roots at Pine Tree, AR. The isolate was stored at $-80^{\circ} \mathrm{C}$ until used. Inoculum was produced on millet seed as described by Mengistu et al. (2007), air dried, and added to seed packets, resulting in $0.5 \mathrm{~g}$ of inoculum $/ 30 \mathrm{~cm}$ of row. Plots were planted 1 June 2011 and 1 June 2012 in Rohwer, AR, and 1 June 2011, 23 May 2012, 31 May 2013, and 17 June 2014 in Stuttgart, AR. The experimental design for each test was a randomized complete block plot design with four replications.

At the R7 growth stage, 10 plants were randomly dug from the outer rows of each plot. The roots were gently washed and the plants air dried for a minimum of 14 days. Colonization was assessed by splitting the roots and stems and rating for discoloration by microsclerotia as described by Mengistu et al. (2007). RSS of each plant was rated with a 1 to 5 scale, where $1=$ no discoloration and $5=$ highly discolored. PHSD was based on the height of internal vascular discoloration from ground level and divided by the total stem height for each plant.

After these assessments were made, the stem above the cotyledonary node was removed and the roots ground in a Wiley Mill (model 4, Arthur H. Thomas Company, Philadelphia, PA) with a 1-mm screen. The ground roots were assayed for root colonization according to a modified procedure by Mengistu et al. (2009). A 0.05-g sample of the ground root tissue from each sample was washed in a 2-ml test tube with $1 \mathrm{ml}$ of $0.525 \% \mathrm{NaOCl}$ (Mengistu et al. 2007). The mixture was mixed for 3-min intervals with a 15 -s pause between mixings. Then the sample was washed with sterile water over a $45-\mu \mathrm{m}$ sieve for $2 \mathrm{~min}$, and the material retained on the sieve was backwashed into a sterile 150-ml Erlenmeyer flask. The blender and sieve were washed with soap and deionized water between samples. To each flask, $50 \mathrm{ml}$ of a selective medium was added, mixed well with the ground root tissue sample, and poured into five Petri dishes. The selective medium used was a modified version of RB medium consisting of PDA (39 g), rifampicin (100 mg), Tergitol NP-10 (1 ml), and deionized water (1 liter) (Cloud and Rupe 1991). The plates were incubated at $33^{\circ} \mathrm{C}$ for 6 to 7 days before colonies were counted. Percent moisture of the root tissue was determined to standardize moisture across samples, and the number of colonies of M. phaseolina was reported as the CFU per gram of dry root tissue, transformed $(\log 10)$ 
Yields were taken from the center two rows of each plot and adjusted to $13 \%$ moisture.

ANOVA for a randomized complete block design for combined years was performed using PROC GLIMMIX of SAS version 9.4 (SAS Institute, Cary, NC). Mean comparisons were made using Fisher's least significant difference $(P<0.05)$. The PROC CORR procedure of SAS was used to compute Pearson's correlation coefficients between the mean of soybean varieties under different field disease screening methods with the mean of the same soybean varieties using the SPA method.

\section{Results}

Eight-cultivar experiment. There were statistically significant differences among soybean genotypes in the first and second trials $(P<0.0001)$ and a statistically significant interaction between trials $(P=0.007)$. Figure 1 shows typical SPA results for susceptible, moderately resistant, and resistant genotypes. The lines with the highest germination in both trials were DT98-7553, DT99-17554, and DT99-17483 (Fig. 2). The lines with the lowest germination or not statistically greater than the lowest germination in both trials were DT97-4290 and LS98-0358. Pharaoh and LS94-3207 had low germination in trial 1 and intermediate germination in trial 2. DT99-16864 had intermediate germination in trial 1 and high germination in trial 2. DT97-4290 had moderate germination in one test and low germination in the other (a susceptible reaction), and Pharaoh had low germination in one test and moderate germination in the other test.

Comparison of SPA with field tests. With SPA, there were significant differences between soybean genotypes in both trials $(P<$ $0.0001)$ and a statistically significant interaction between trials $(P<0.0001)$. There were seven cultivars that were not significantly different from the cultivar with the highest germination in both trials: R01-581F, DK4866, JTN-4307, JTN-5208, CPLRC5007, Osage, and CPLRC5663 (Fig. 3). Eight cultivars had significantly

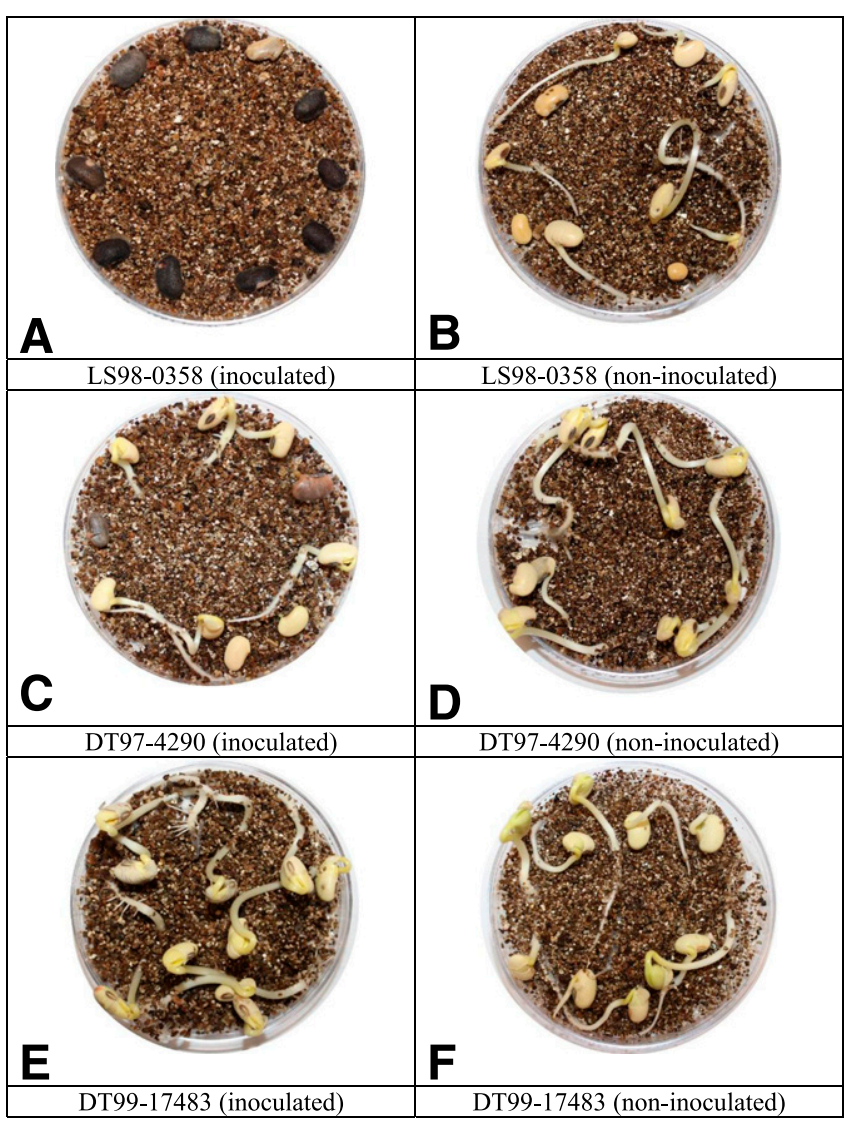

Fig. 1. Seed plate assay disease assessment showing results for susceptible genotype LS98-0358 (A, B), moderately resistant DT97-4290 (C, D), and resistant genotype DT99-17483 (E, F), inoculated with Macrophomina phaseolina and noninoculated. lower germination than these cultivars in both trials: Hutcheson, Spencer, Jack, NK539-A3, K07-1544, Pharaoh, LS98-0358, and EXP1-Stine39LA02. DT97-4290 was not significantly different from the cultivar with the highest germination in trial 1 (CPLRC5663) but was not significantly different from the cultivar with the lowest germination in trial 2 (Hutcheson). Eight lines had either moderate or low germination in both tests, and these levels of germination were statistically different from the seven lines with high germination. Three lines had moderate germination in both tests: EXP1-Stine39LA02, EXP2-XC3810, and MorSoy RT5388N. Three lines were in both this test and the eight-cultivar test: Pharaoh,
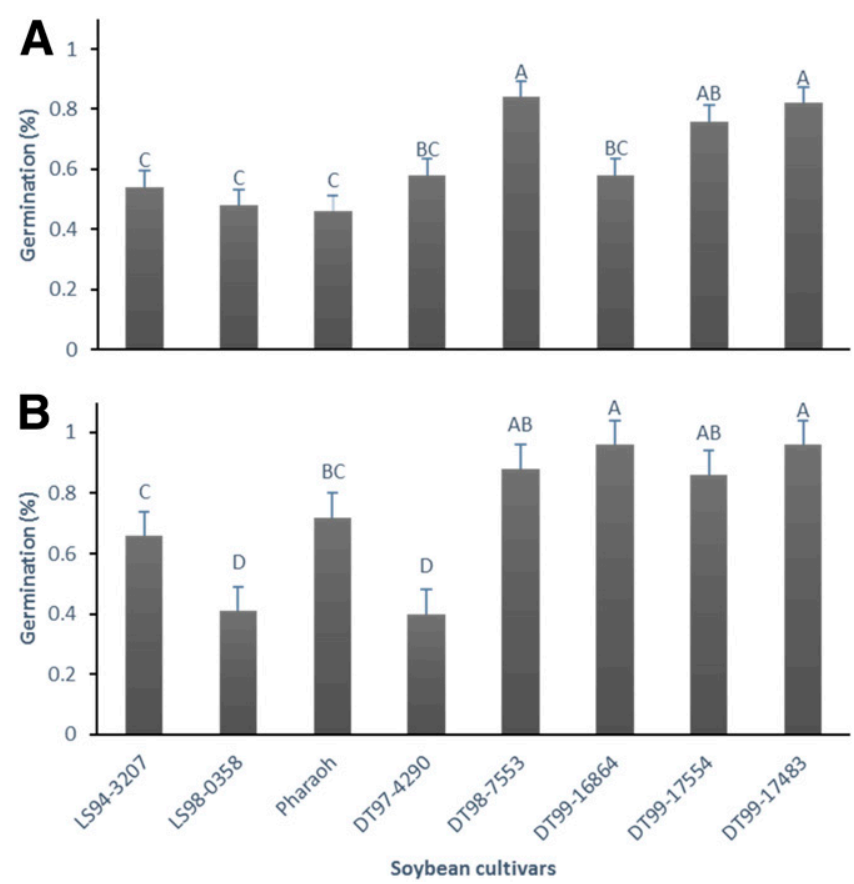

Fig. 2. Percent seed germination of eight soybean cultivars in the first (A) and second (B) trials of the seed plate assay. Bars with the same letter are not significantly different according to the LSD test, $\alpha=0.05$.
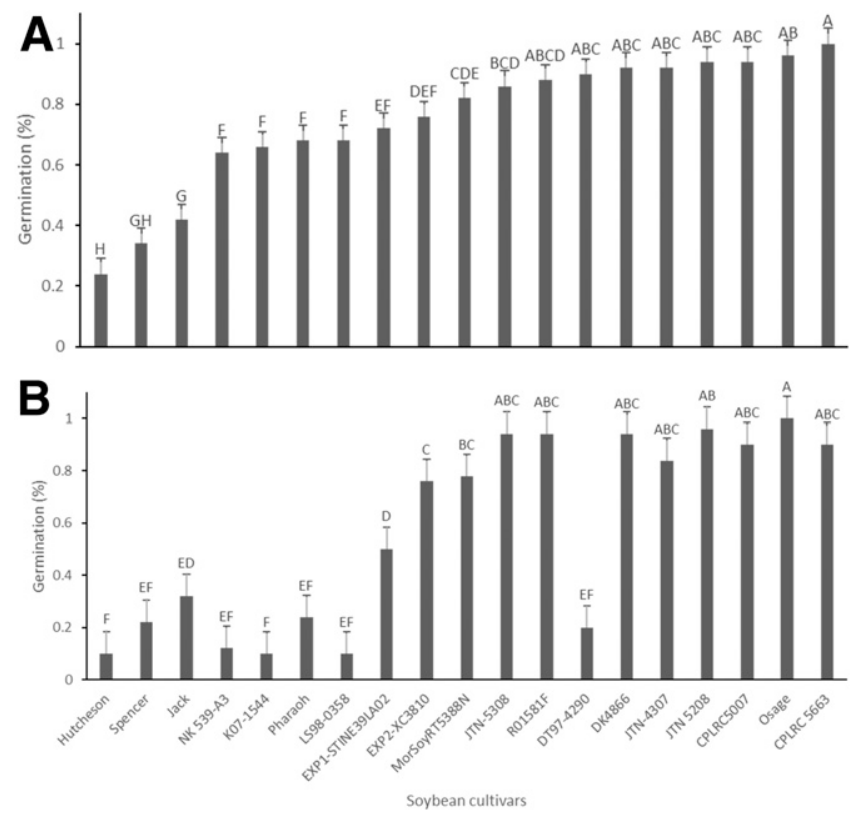

Fig. 3. Percent seed germination of 19 soybean cultivars in the first (A) and second (B) trials of the seed plate assay. Bars with the same letter are not significantly different according to the LSD test, $\alpha=0.05$. 
LS98-0358, and DT97-4290. Pharaoh and LS98-0358 had either very low or moderate germination, but significantly lower germination than the most resistant line. DT97-4290 had very high germination in the first test and very low germination in the second test.

Field data experiments. The ANOVAs for CFU, RSS, PHSD, and yield of 14 cultivars grown at Rohwer in 2011 and 2012 are presented in Table 1 . There were significant maturity group (MG) effects for CFU and yield and significant genotype (MG) effects for $\mathrm{CFU}$ and RSS. There was no clear effect of $\mathrm{MG}$ on CFU (Table 2). The greatest CFUs occurred in MG IV and the lowest in Late MG III, but CFU levels for MG II and MG V were not significantly different from those of MG IV. There was a clear effect of MG on yield. MG V had the highest yield, and MG II had the lowest yield (Table 3 ). There were significant cultivar differences in CFUs. R01-581F had the greatest CFUs, and Jack, NK539-A3, DK4866, JTN-4307, DT97-4290, LS98-0358, and CPLRC5007 had CFU levels not significantly different from R01-581F (Table 2). K07-1544 had the lowest CFUs, and EXP1-Stine39LA02, EXP2-XC3810, Pharaoh, and MorSoy RT5388N were not significantly different than K07-1544. Spencer had the greatest RSS ratings, and Jack, K071544, NK539-A3, EXP2-XC3810, DK4866, DT97-4290, LS980358, CPLRC5007, and MorSoy RT5388N were not significantly different from Spencer. JTN-4307 had the lowest RSS, and EXP1Stine39LA02 was not significantly different. There was no significant

Table 1. Analysis of variance for colony forming units (CFU), root and stem severity (RSS), and percent height stem discoloration (PHSD) caused by Macrophomina phaseolina and yield of 14 soybean genotypes measured at Rohwer, AR, from 2011 to 2012

\begin{tabular}{llcccc}
\hline Parameter & \multicolumn{1}{c}{ Effect } & DF $^{\mathbf{x}}$ & Den DF $^{\mathbf{x}}$ & $\boldsymbol{F}$ value & $\boldsymbol{P}$ value \\
\hline CFU $^{\mathrm{y}}$ & MG $^{\mathrm{z}}$ & 6 & 36 & 2.54 & 0.0374 \\
& Genotype (MG) & 7 & 36 & 4.61 & 0.0009 \\
RSS & MG & 5 & 3.874 & 2.24 & 0.2323 \\
& Genotype (MG) & 8 & 7.045 & 5.94 & 0.0146 \\
PHSD & MG & 5 & 4.336 & 1.93 & 0.2611 \\
& Genotype (MG) & 6 & 6.145 & 2.51 & 0.141 \\
Yield & MG & 7 & 6.996 & 5.43 & 0.0193 \\
& Genotype (MG) & 10 & 11.57 & 1.83 & 0.1531 \\
\hline
\end{tabular}

${ }^{\mathrm{x}} \mathrm{DF}=$ degrees of freedom; and Den DF $=\mathrm{DF}$ associated with the model errors.

y CFU means in $\log 10$ values data for only in 2011.

${ }^{\mathrm{z}} \mathrm{MG}=$ maturity group

Table 2. Effect of soybean cultivar on colony forming units per gram of root (CFU) and root and stem severity (RSS) by Macrophomina phaseolina at Rohwer, AR, in 2011 and 2012

\begin{tabular}{llll}
\hline Cultivar & \multicolumn{1}{c}{ MGw $^{\mathbf{w}}$} & \multicolumn{1}{c}{ CFU $^{\mathbf{x}}$} & \multicolumn{1}{c}{ RSS $^{\mathbf{y}}$} \\
\hline Jack & II & $4.16 \mathrm{abc}^{\mathbf{z}}$ & $2.91 \mathrm{abc}$ \\
K07-1544 & III & $3.76 \mathrm{e}$ & $3.33 \mathrm{ab}$ \\
NK539-A3 & III & $4.35 \mathrm{abc}$ & $2.92 \mathrm{abc}$ \\
EXP1-Stine39LA02 & Late III & $4.03 \mathrm{cde}$ & $2.57 \mathrm{~cd}$ \\
EXP2-XC3810 & Late III & $3.81 \mathrm{de}$ & $3.04 \mathrm{abc}$ \\
Spencer & Early IV & $4.12 \mathrm{bcd}$ & $3.41 \mathrm{a}$ \\
DK4866 & IV & $4.27 \mathrm{abc}$ & $2.98 \mathrm{abc}$ \\
JTN-4307 & IV & $4.17 \mathrm{abc}$ & $1.9 \mathrm{~d}$ \\
DT97-4290 & IV & $4.42 \mathrm{ab}$ & $2.79 \mathrm{abc}$ \\
LS98-0358 & Late IV & $4.36 \mathrm{abc}$ & $3.11 \mathrm{abc}$ \\
Pharaoh & Late IV & $3.89 \mathrm{cde}$ & $2.68 \mathrm{bc}$ \\
R01-581F & V & $4.51 \mathrm{a}$ & $2.61 \mathrm{c}$ \\
CPLRC5007 & V & $4.49 \mathrm{a}$ & $2.83 \mathrm{abc}$ \\
MorSoy RT5388N & V & $3.85 \mathrm{cde}$ & $2.69 \mathrm{abc}$ \\
\hline
\end{tabular}

${ }^{\mathrm{w}} \mathrm{MG}=$ maturity group.

${ }^{x}$ CFU means in $\log 10$ values data for 2011 only.

y Based on 1 to 5 severity scale (Mengistu et al. 2007).

${ }^{\mathrm{z}}$ Means with the same letter are not significantly different according to the LSD test, $\alpha=0.05$. effect of either MG or genotype (MG) for PHSD, which averaged 0.08 across the tests.

At Stuttgart from 2011 to 2014, there was a significant MG effect for RSS and significant genotype (MG) effects for PHSD, RSS, and CFU (Table 4). There was no clear MG trend with RSS (Table 5). The greatest RSS ratings were in MGs II, Late IV, and V and the lowest with MGs III, Late III, and IV. PHSD was greatest for R01-581F and lowest for EXP1-Stine39LA02 (Table 6). RSS was greatest for LS98-0358 and lowest for DT97-4290. CFUs were greatest for NK539-A3 and lowest for JTN-5308. There were no significant differences in yields, with an average yield of $265.64 \mathrm{~kg} / \mathrm{ha}$ across the test.

There were significant positive correlations of SPA with yield at Rohwer in 2011 and 2012 and at Stuttgart in 2011, 2013, and 2014 (Table 7). PHSD, RSS, and CFU were not correlated with yield at either location or in any year. SPA was negatively correlated with RSS at Rohwer in 2012, with CFU at Stuttgart in 2012, and with PHSD at

Table 3. Effect of soybean maturity group (MG) on root colonization by $\mathrm{Mac}$ rophomina phaseolina measured as colony forming units per gram of root (CFU) and yield (kg/ha) at Rohwer, AR, in 2011 and 2012

\begin{tabular}{lll}
\hline MG & CFU $^{\mathbf{y}}$ & Yield \\
\hline II & $4.16 \mathrm{abc}^{\mathbf{z}}$ & $1.10 \mathrm{c}$ \\
III & $4.06 \mathrm{bc}$ & $2.55 \mathrm{bc}$ \\
Late III & $3.92 \mathrm{c}$ & $2.83 \mathrm{bc}$ \\
Early IV & $4.12 \mathrm{abc}$ & $3.33 \mathrm{ab}$ \\
IV & $4.29 \mathrm{a}$ & $4.67 \mathrm{ab}$ \\
Late IV & $4.13 \mathrm{abc}$ & $3.49 \mathrm{ab}$ \\
V & $4.28 \mathrm{ab}$ & $4.74 \mathrm{a}$ \\
\hline
\end{tabular}

y CFU means in $\log 10$ values data for 2011.

${ }^{\mathrm{z}}$ Means with the same letter are not significantly different according to the LSD test, $\alpha=0.05$

Table 4. Analysis of variance for percent height of stem internal discoloration (PHSD), root stem severity (RSS), and colony forming unit (CFU) assessment methods of 14 soybean genotypes measured at Stuttgart, AR, from 2011 to 2014

\begin{tabular}{llrccc}
\hline Parameter & \multicolumn{1}{c}{ Effect } & DF $^{\mathbf{y}}$ & Den DF $^{\mathbf{y}}$ & $\boldsymbol{F}$ value & $\boldsymbol{P}$ value \\
\hline PHSD & MG $^{\mathbf{z}}$ & 6 & 19.63 & 0.51 & 0.7934 \\
& Genotype (MG) & 11 & 32.96 & 4.08 & 0.0008 \\
RSS & MG & 6 & 29.01 & 2.5 & 0.0454 \\
& Genotype (MG) & 11 & 39.38 & 2.82 & 0.0082 \\
CFU & MG & 6 & 23 & 1.45 & 0.2396 \\
& Genotype (MG) & 11 & 37.11 & 2.57 & 0.0158 \\
Yield & MG & 6 & 19.53 & 1.82 & 0.1478 \\
& Genotype (MG) & 11 & 235.1 & 0.76 & 0.6773 \\
\hline
\end{tabular}

${ }^{y} \mathrm{DF}=$ degrees of freedom; and Den DF = DF associated with the mode errors.

${ }^{\mathrm{z}} \mathrm{MG}=$ maturity group.

Table 5. Effect of soybean maturity group (MG) on internal root and stem discoloration (RSS) at Stuttgart, AR, from 2011 to 2014

\begin{tabular}{ll}
\hline MG & RSS $^{\mathbf{y}}$ \\
\hline II & $3.93 \mathrm{a}^{\mathbf{z}}$ \\
III & $3.54 \mathrm{~b}$ \\
Late III & $3.54 \mathrm{~b}$ \\
Early IV & $3.71 \mathrm{ab}$ \\
IV & $3.51 \mathrm{~b}$ \\
Late IV & $3.91 \mathrm{a}$ \\
V & $3.62 \mathrm{ab}$ \\
\hline
\end{tabular}

${ }^{\mathrm{y}}$ Visible internal root colonization by Macrophomina phaseolina measured a 1 to 5 scale (Mengistu et al. 2007).

${ }^{\mathrm{z}}$ Means with the same letter are not significantly different according to the LSD test, $\alpha=0.05$. 
Table 6. Effect of soybean genotype as percent height stem discoloration (PHSD), root and stem severity (RSS), and colony forming units per gram of root (CFU) by Macrophomina phaseolina at Stuttgart, AR, from 2011 to 2014

\begin{tabular}{lllll}
\hline Cultivar & \multicolumn{1}{c}{ MG $^{\mathbf{v}}$} & PHSD $^{\mathbf{w}}$ & \multicolumn{1}{c}{ RSS $^{\mathbf{x}}$} & CFU $^{\mathbf{y}}$ \\
\hline Jack & II & $0.13 \mathrm{bc}^{\mathrm{z}}$ & $3.93 \mathrm{ab}$ & $4.49 \mathrm{ab}$ \\
NK539-A3 & III & $0.20 \mathrm{abc}$ & $3.70 \mathrm{abcdefg}$ & $4.63 \mathrm{a}$ \\
K07-1544 & III & $0.21 \mathrm{abc}$ & $3.37 \mathrm{efg}$ & $4.52 \mathrm{ab}$ \\
EXP1-Stine39LA02 & Late III & $0.103 \mathrm{c}$ & $3.48 \mathrm{cdefg}$ & $4.55 \mathrm{ab}$ \\
EXP2-XC3810 & Late III & $0.17 \mathrm{bc}$ & $3.59 \mathrm{bcdefg}$ & $4.53 \mathrm{ab}$ \\
Spencer & Early IV & $0.19 \mathrm{abc}$ & $3.71 \mathrm{abcdefg}$ & $4.47 \mathrm{abc}$ \\
DT97-4290 & IV & $0.15 \mathrm{bc}$ & $3.33 \mathrm{~g}$ & $4.33 \mathrm{bcd}$ \\
JTN-4307 & IV & $0.15 \mathrm{bc}$ & $3.40 \mathrm{defg}$ & $4.43 \mathrm{abc}$ \\
DK4866 & IV & $0.17 \mathrm{bc}$ & $3.81 \mathrm{abc}$ & $4.46 \mathrm{abc}$ \\
LS98-0358 & Late IV & $0.19 \mathrm{bc}$ & $4.03 \mathrm{a}$ & $4.57 \mathrm{ab}$ \\
Pharaoh & Late IV & $0.21 \mathrm{abc}$ & $3.79 \mathrm{abcd}$ & $4.48 \mathrm{abc}$ \\
R01-581F & V & $0.33 \mathrm{a}$ & $4.00 \mathrm{a}$ & $4.52 \mathrm{ab}$ \\
Osage & V & $0.25 \mathrm{ab}$ & $3.66 \mathrm{abcdefg}$ & $4.32 \mathrm{bcd}$ \\
MorSoy RT5388N & V & $0.23 \mathrm{abc}$ & $3.76 \mathrm{abcde}$ & $4.20 \mathrm{dc}$ \\
CPLRC5007 & V & $0.20 \mathrm{abc}$ & $3.45 \mathrm{cdefg}$ & $4.35 \mathrm{abc}$ \\
CPLRC5663 & V & $0.20 \mathrm{abc}$ & $3.75 \mathrm{abcdef}$ & $4.31 \mathrm{bcd}$ \\
JTN-5308 & V & $0.16 \mathrm{bc}$ & $3.37 \mathrm{fg}$ & $4.11 \mathrm{~d}$ \\
JTN-5208 & V & $0.14 \mathrm{bc}$ & $3.34 \mathrm{~g}$ & $4.21 \mathrm{dc}$ \\
\hline
\end{tabular}

${ }^{\mathrm{v}} \mathrm{MG}=$ maturity group.

${ }^{w}$ Percent height of stem internal discoloration caused by M. phaseolina (Mengistu et al. 2007).

x Visible internal root colonization by $M$. phaseolina measured a 1 to 5 scale (Mengistu et al. 2007).

y CFU per gram of root by M. phaseolina (Mengistu et al. 2007).

$\mathrm{z}$ Means with the same letter are not significantly different according to the LSD test, $\alpha=0.05$.
Rohwer in 2012 and at Stuttgart in 2011 and 2012. PHSD was positively correlated with SPA at Stuttgart in 2013.

\section{Discussion}

The SPA consistently assessed the relative reaction of most soybean lines to infection by M. phaseolina. In the first test, eight cultivars were compared. These cultivars were selected based on published reactions to charcoal rot: five resistant lines (DT974290, DT98-7553, DT99-16864, DT99-17554, and DT99-17483) and three susceptible lines (LS94-3207, LS98-0358, and Pharaoh) (Luna et al. 2017; Twizeyimana et al. 2012). Three of these lines gave a resistant reaction, having germination levels that were the highest or were not significantly different from the highest germination in each test. These lines were DT98-7553, DT99-17554, and DT9917483. LS94-3207 and LS98-0358 had susceptible reactions in both tests (low germination). There were some differences in cultivar reactions between tests. DT99-16864 had high germination in one test and moderate in the other.

Similarly, in the 18-cultivar test, seven lines had high germination in both tests, indicating a resistant reaction, and were not statistically different from each other. This variability in reaction of these three lines was observed in the field studies. However, SPA consistently identified resistant and susceptible lines with clear statistical separations for most soybean lines.

There was a great deal of variability in cultivar reaction between locations and between assessment methods within a location using field-screening methods (PHSD, RSS, and CFU). Pharaoh and DT97-4290 are examples of variation between locations. At Rohwer, Pharaoh had very low levels of RSS and CFU, but it had high levels

Table 7. Correlation matrix of three soybean charcoal rot disease assessment methods and yield with seed plate assay, evaluated in 2011 and 2012 at Rohwer, AR, and from 2011 to 2014 at Stuttgart, AR

\begin{tabular}{|c|c|c|c|c|c|c|c|}
\hline Location & Year & Parameter & Yield & PHSD $^{t}$ & $\mathbf{R S S}^{\mathbf{u}}$ & $\mathrm{CFU}^{\mathrm{v}}$ & $\overline{\text { SPA }^{w}}$ \\
\hline \multirow[t]{5}{*}{ Rohwer } & 2011 & Yield & 1.00 & $0.04 \mathrm{NS}^{\mathrm{x}}$ & $-0.20 \mathrm{NS}$ & $0.10 \mathrm{NS}$ & $0.65^{y}$ \\
\hline & & PHSD & $-0.04 \mathrm{NS}$ & 1 & $0.52 \mathrm{NS}$ & $0.10 \mathrm{NS}$ & $-0.45 \mathrm{NS}$ \\
\hline & & RSS & $-0.20 \mathrm{NS}$ & $0.52 \mathrm{NS}$ & 1 & $-0.05 \mathrm{NS}$ & $-0.32 \mathrm{NS}$ \\
\hline & & CFU & $0.10 \mathrm{NS}$ & $0.10 \mathrm{NS}$ & $-0.05 \mathrm{NS}$ & 1 & $0.24 \mathrm{NS}$ \\
\hline & & SPA & $0.65^{\mathrm{y}}$ & $0.45 \mathrm{NS}$ & $-0.32 \mathrm{NS}$ & $0.24 \mathrm{NS}$ & 1 \\
\hline \multirow[t]{5}{*}{ Rohwer } & 2012 & Yield & 1.00 & $-0.39 \mathrm{NS}$ & $-0.06 \mathrm{NS}$ & $\mathrm{ND}^{\mathrm{z}}$ & $0.70^{\mathrm{y}}$ \\
\hline & & PHSD & $-0.39 \mathrm{NS}$ & 1 & $0.69^{\mathrm{y}}$ & ND & $-0.69^{y}$ \\
\hline & & RSS & $-0.06 \mathrm{NS}$ & $0.69^{y}$ & 1 & ND & $-0.60^{y}$ \\
\hline & & $\mathrm{CFU}$ & ND & ND & ND & ND & ND \\
\hline & & SPA & $0.70^{y}$ & $-0.69^{y}$ & $-0.60^{\mathrm{y}}$ & ND & 1 \\
\hline \multirow[t]{5}{*}{ Stuttgart } & 2011 & Yield & 1.00 & $-0.27 \mathrm{NS}$ & $-0.17 \mathrm{NS}$ & $-0.22 \mathrm{NS}$ & $0.65^{y}$ \\
\hline & & PHSD & $-0.27 \mathrm{NS}$ & 1 & $0.47 \mathrm{NS}$ & $0.75^{\mathrm{y}}$ & $-0.56^{y}$ \\
\hline & & RSS & $-0.17 \mathrm{NS}$ & $0.47 \mathrm{y}$ & 1 & $0.61^{\mathrm{y}}$ & $-0.12 \mathrm{NS}$ \\
\hline & & $\mathrm{CFU}$ & $-0.22 \mathrm{NS}$ & $0.75^{y}$ & $0.61^{\mathrm{y}}$ & 1 & $-0.31 \mathrm{NS}$ \\
\hline & & SPA & $0.65^{y}$ & $-0.56^{\mathrm{y}}$ & $-0.12 \mathrm{NS}$ & $-0.31 \mathrm{NS}$ & 1 \\
\hline \multirow[t]{5}{*}{ Stuttgart } & 2012 & Yield & 1.00 & $0.36 \mathrm{NS}$ & $-0.08 \mathrm{NS}$ & $0.31 \mathrm{NS}$ & $-0.09 \mathrm{NS}$ \\
\hline & & PHSD & $0.36 \mathrm{NS}$ & 1 & $0.46^{\mathrm{y}}$ & $0.67^{y}$ & $-0.59^{y}$ \\
\hline & & RSS & $-0.08 \mathrm{NS}$ & $0.46^{y}$ & 1 & $0.34 \mathrm{NS}$ & $-0.44 \mathrm{NS}$ \\
\hline & & $\mathrm{CFU}$ & $0.31 \mathrm{NS}$ & $0.67^{y}$ & $0.34 \mathrm{NS}$ & 1 & $-0.64^{\mathrm{y}}$ \\
\hline & & SPA & $-0.09 \mathrm{NS}$ & $-0.59^{y}$ & $-0.44 \mathrm{NS}$ & $-0.64^{y}$ & 1 \\
\hline \multirow[t]{5}{*}{ Stuttgart } & 2013 & Yield & 1.00 & $0.50^{\mathrm{y}}$ & $0.11 \mathrm{NS}$ & $-0.40 \mathrm{NS}$ & $0.48^{y}$ \\
\hline & & PHSD & $0.50^{\mathrm{y}}$ & 1 & $-0.02 \mathrm{NS}$ & $0.41 \mathrm{NS}$ & $0.79^{y}$ \\
\hline & & RSS & $0.11 \mathrm{NS}$ & $0.02 \mathrm{NS}$ & 1 & $0.61^{\mathrm{y}}$ & $-0.17 \mathrm{NS}$ \\
\hline & & $\mathrm{CFU}$ & $-0.40 \mathrm{NS}$ & $-0.41 \mathrm{NS}$ & $0.61^{\mathrm{y}}$ & 1 & $-0.40 \mathrm{NS}$ \\
\hline & & SPA & $0.48^{\mathrm{y}}$ & $0.79 \mathrm{y}$ & $-0.17 \mathrm{NS}$ & $-0.40 \mathrm{NS}$ & 1 \\
\hline \multirow[t]{5}{*}{ Stuttgart } & 2014 & Yield & 1.00 & $0.31 \mathrm{NS}$ & $0.05 \mathrm{NS}$ & $-0.16 \mathrm{NS}$ & $0.57^{y}$ \\
\hline & & PHSD & $0.31 \mathrm{NS}$ & 1 & $0.60^{\mathrm{y}}$ & $0.59^{y}$ & $0.52 \mathrm{NS}$ \\
\hline & & RSS & $0.05 \mathrm{NS}$ & $0.60^{y}$ & 1 & $0.79^{y}$ & $-0.08 \mathrm{NS}$ \\
\hline & & $\mathrm{CFU}$ & $-0.16 \mathrm{NS}$ & $0.59^{\mathrm{y}}$ & $0.79^{y}$ & 1 & $0.12 \mathrm{NS}$ \\
\hline & & SPA & $0.57^{y}$ & $0.52 \mathrm{NS}$ & $-0.08 \mathrm{NS}$ & $0.12 \mathrm{NS}$ & 1 \\
\hline
\end{tabular}

${ }^{t}$ Percent height of stem internal discoloration caused by Macrophomina phaseolina (Mengistu et al. 2007).

u Visible internal root colonization by M. phaseolina measured a 1 to 5 scale (Mengistu et al. 2007).

${ }^{\vee}$ Colony-forming units per gram of root by M. phaseolina (Mengistu et al. 2007).

${ }^{\mathrm{w}}$ Seed plate assay.

$\times \mathrm{NS}=$ not significant $(P>0.05)$.

y Significant at the 0.05 probability level.

${ }^{\mathrm{z}} \mathrm{ND}=$ no data. 
at Stuttgart, whereas DT97-4290 had high levels at Rohwer and low levels at Stuttgart. In most reports, DT97-4290 was listed as resistant or moderately resistant based on PHSD, RSS, or CFU (Mengistu et al. 2007) or with the cut-stem method (Twizeyimana et al. 2012), but Pawlowski et al. (2015) reported that this line was moderately susceptible using the cut-stem method. Other cultivars varied in reaction based on the assay method within a location. For example, K07-1544 had a high RSS rating but low CFU at Rohwer, and low RSS but high PHSD and CFU at Stuttgart. This cultivar gave a susceptible reaction with SPA. Site-to-site differences in overall assessments might be owing to differences in environmental factors. Soil types were different (Rohwer a Sharkey silty clay and Stuttgart a Crowley silt loam), but at both sites plots were not irrigated and were planted late to enhance plant stress. In addition, all plots were inoculated with the same strain of $M$. phaseolina, so disease pressure should have been high at both locations. Differences between assessment methods within a location are more difficult to explain. All three field methods are assessing the same trait, namely, colonization of the plant by M. phaseolina at the end of the season. PHSD and RSS are visual assessments based on the presence of microsclerotia, whereas CFU measures colonization based on plating (Mengistu et al. 2007). Not surprisingly, these methods were significantly and positively correlated to each other: PHSD was correlated to RSS in four of six comparisons and to CFU in three of five comparisons, and RSS was correlated to CFU in three of five comparisons. These methods were not correlated to yield at either location or in any year, except that PHSD was correlated to yield at Stuttgart in 2013, but this correlation was positive, indicating the greater the colonization the greater the yield. Unlike the other measures, which were not significantly correlated to yield, SPA was positively correlated to yield in five the six comparisons, indicating that SPA was a better predictor of cultivar performance under charcoal rot-favorable conditions than the end-of-the-season assessments PHSD, RSS, and CFU.

MG had a significant effect on CFU and yield at Rohwer and on RSS at Stuttgart. Although significant, there was no clear trend of MG with CFU or RSS. Both high and low levels of these measures occurred with early as well as late MGs. This agrees with a previous report that did not find a maturity effect on CFU (Mengistu et al. 2014). There was a clear trend of MG with yield at Rohwer, where yields increased with increases in maturity, but this did not occur at Stuttgart, where there was no significant MG effect on yield.

This paper presents a promising new assessment method for charcoal rot resistance in soybean. SPA gave consistent results across a range of cultivars and was consistently related to cultivar performance as measured by yield under charcoal rot-favorable field conditions. This was not the case with the end-of-season assessments PHSD, RSS, and CFU. In addition, SPA is a relatively rapid screening method: 2 weeks for SPA compared with 8 weeks for the cutstem method and an entire growing season for PHSD, RSS, and CFU. SPA also takes up much less space than any of the other methods. However, SPA, like the other assessments, is an indirect measure of charcoal rot resistance. This is because we cannot induce charcoal rot symptoms in the field or greenhouse. The standard assessment method, CFU and its related measures RSS and PHSD, measures colonization of the plant by $M$. phaseolina at R7. At this growth stage, the plant is senescing, colonization is rapidly increasing (Kendig et al. 2000; Mengistu et al. 2011; Short et al. 1978), and seed fully developed. It is not clear how this colonization is related to yield loss. Smith and Carvil (1997) reported a strong relationship between CFU and yield, but we did not find that CFU, RSS, or PHSD were related to yield under our experimental conditions. Active plant response to $M$. phaseolina is measured by SPA and the cut-stem method, but these methods measure seed rot and seedling stem cankers, respectively, which are not symptoms associated with charcoal rot in the field (Mengistu et al. 2015). Assessments of charcoal rot during the season are few. Mengistu et al. (2007) followed leaf senesce during reproductive development as a measure of charcoal rot impact but rejected this as a meaningful assessment method because these results did not agree with those of CFU. Doubledee et al. (2018), in a study with microplots infested or not infested with
M. phaseolina, found that infestation was associated with decreased stomatal conductance and increased canopy temperature and, in the second year of the study, found that these differences occurred with susceptible but not resistant cultivars. However, hyperspectral assessments of these plots did not find a reflective index that was consistently associated with $M$. phaseolina infestation that could be used for cultivar resistance screening. At this time, it may be that soybean cultivar screenings for charcoal rot resistance will rely on both endof-season assessments (CFU, RSS, and PHSD) and greenhouse or laboratory methods (cut stem and SPA). Our results demonstrate that SPA could be an effective new screening method for charcoal rot resistance.

\section{Acknowledgments}

Special thanks to Robert Holland and Adele Steger for the field assessment of charcoal rot, and to Randy Cingolani and Larry Earnest at the Southeast Research Station, Rohwer, AR, and to Jonathan McCoy at the Rice Research and Extension Center, Stuttgart, AR, for their help in maintaining the field plots.

\section{Literature Cited}

Altier, N. A., and Thies, J. A. 1995. Identification of resistance to Pythium seedling diseases in alfalfa using a culture plate method. Plant Dis. 79:341-346.

Avanzato, M. V. 2011. Characterization of Pythium and Fusarium species associated with soybean seeds and seedlings. Ph.D. dissertation. University of Arkansas, Fayetteville, AR.

Baird, R. E., and Brock, J. H. 1999. First report of Macrophomina phaseolina on cotton (Gossypium hirsutum) in Georgia. Plant Dis. 83:487.

Bowen, C. R., and Schapaugh, W. T. 1989. Relationships among charcoal rot infection, yield, and stability estimates in soybean blends. Crop Sci. 29:42-46.

Bristow, P. R., and Wyllie, T. D. 1986. Macrophomina phaseolina, another cause of the twin-stem abnormality disease of soybean. Plant Dis. 70:1152-1153.

Broders, K. D., Lipps, P. E., Paul, P. A., and Dorrance, A. E. 2007. Characterization of Pythium spp. associated with corn and soybean seed and seedling disease in Ohio. Plant Dis. 91:727-735.

Cloud, G. L., and Rupe, J. C. 1991. Morphological instability on a chlorate medium of isolates of Macrophomina phaseolina from soybean and sorghum. Phytopathology 81:892-895

Collins, D. J., Wyllie, T. D., and Anderson, S. H. 1991. Biological activity of Macrophomina phaseolina in soil. Soil Biol. Biochem. 23:495-496.

Cross, C., Wrather, A., Fothergill, K., Shannon, G., Li, S., Shumway, C., and Rupe, J. 2012. Effect of lactofen, azoxystrobin, and genotypes on charcoal rot, Phomopsis seed decay, and pod and stem blight in soybean. Plant Dis. 96:1154-1158

Dhingra, O. D., and Sinclair, J. B. 1978. Biology and Pathology of Macrophomina phaseolina. Imprensa Universitária, Universidade Federal de Viçosa, Viçosa, Brazil.

Doubledee, M. D., Rupe, J. C., Rothrock, C. S., and Bajwa, S. G. 2018. Effect of root infection by Macrophomina phaseolina on stomatal conductance, canopy temperature and yield of soybean. Can. J. Plant Pathol. 40:272-283.

Francl, L. J., Wyllie, T. D., and Rosenbrock, S. M. 1988. Influence of crop rotation on population density of Macrophomina phaseolina in soil infested with Heterodera glycines. Plant Dis. 72:760-764.

Goidanish, G. 1947. Revisione del genere Macrophomina Petrak. Specie tipica: Macrophomina phaseolina (Tass.) Goid. nov. comb. nec. M. Phaseoli (Maubl.). Ann. Sperimentazione Agrar. 1:449-461.

Grodzki, W., McManus, M., Knížek, M., Meshkova, V., Mihalciuc, V., Novotny, J., Turčani, M., and Slobodyang, Y. 2004. Occurrence of spruce bark beetles in forest stands at different levels of air pollution stress. Environ. Pollut. 130:73-83.

Kendig, S. R., Rupe, J. C., and Scott, H. D. 2000. Effect of irrigation and soil water stress on densities of Macrophomina phaseolina in soil and roots of two soybean cultivars. Plant Dis. 84:895-900.

Kittle, D. R., and Gray, L. E. 1982. Response of soybeans and soybean pathogens to soil fumigation and foliar fungicide sprays. Plant Dis. 66:213-215.

Luna, R. P. M., Mueller, D., Mengistu, A., Singh, A. K., Hartman, G. L., and Wise, K. A. 2017. Advancing our understanding of charcoal rot in soybeans. J. Integr. Pest Manag. 8. doi: 10.1093/jipm/pmw020.

Mengistu, A., Arelli, P., Bond, J., Nelson, R., Rupe, J., Shannon, G., and Wrather, A. 2013. Identification of soybean accessions resistant to Macrophomina phaseolina by field screening and laboratory validation. Plant Health Prog. 14. doi: 10.1094/PHP-2013-0318-01-RS.

Mengistu, A., Ray, J.D., Smith, J. R., and Boykin, D. L. 2014. Maturity effects on colony-forming units of Macrophomina phaseolina infection as measured using near-isogenic lines of soybean. J. Crop Improv. 28:38-56.

Mengistu, A., Ray, J. D., Smith, J. R., and Paris, R. L. 2007. Charcoal rot disease assessment of soybean genotypes using a colony-forming unit index. Crop Sci. 47:2453-2461.

Mengistu, A., Reddy, K. N., Zablotowicz, R. M., and Wrather, A. J. 2009 Propagule densities of Macrophomina phaseolina in soybean tissue and soil as affected by tillage, cover crop, and herbicide. Plant Health Prog. 10. doi: 10.1094/PHP-2009-0130-01-RS. 
Mengistu, A., Smith, J. R., Ray, J. D., and Bellaloui, N. 2011. Seasonal progress of charcoal rot and its impact on soybean productivity. Plant Dis. 95:1159-1166.

Mengistu, A., Wrather, A., and Rupe, J. C. 2015. Charcoal rot. Pages 67-69 in: Compendium of Soybean Diseases. G. L. Hartman, J. C. Rupe, E. J. Sikora, L. L. Domier, J. A. Davis, and K. L. Steffey, eds. American Phytopathological Society, St. Paul, MN.

Munkvold, G. P., and O'Mara, J. K. 2002. Laboratory and growth chamber evaluation of fungicidal seed treatments for maize seedling blight caused by Fusarium species. Plant Dis. 86:143-150.

Pawlowski, M. L., Hill, C. B., and Hartman, G. L. 2015. Resistance to charcoal rot identified in ancestral soybean germplasm. Crop Sci. 55:1230-1235.

Pearson, C. A. S., Schwenk, F. W., Crowe, F. J., and Kelley, K. 1984. Colonization of soybean roots by Macrophomina phaseolina. Plant Dis. 68:1086-1088.

Sandermann, H., Jr. 2004. Molecular ecotoxicology of plants. Trends Plant Sci. 9:406-413.

Short, G. E., Wyllie, T. D., and Ammon, V. D. 1978. Quantitative enumeration of Macrophomina phaseolina in soybean tissues. Phytopathology 68:736-741.

Smith, G. S., and Carvil, O. N. 1997. Field screening of commercial and experimental soybean cultivars for their reaction to Macrophomina phaseolina. Plant Dis. 81: 363-368.

Su, G., Suh, S.-O., Schneider, R. W., and Russin, J. S. 2001. Host specialization in the charcoal rot fungus, Macrophomina phaseolina. Phytopathology 91:120-126.
Twizeyimana, M., Hill, C. B., Pawlowski, M., Paul, C., and Hartman, G. L. 2012 A cut-stem inoculation technique to evaluate soybean for resistance to Macrophomina phaseolina. Plant Dis. 96:1210-1215.

Urrea, K., Rupe, J., Chen, P., and Rothrock, C. S. 2017. Characterization of seed rot resistance to Pythium aphanidermatum in soybean. Crop Sci. 57: 1394-1403.

Watanabe, T., Smith, S., and Snyder, W. 1970. Population of Macrophomina phaseolina in soil as affected by fumigation and cropping. Phytopathology 60:1717-1719.

Wrather, J. A., Shannon, J. G., Carter, T. E., Bond, J. P., Rupe, J. C., and Almeida, A. M. 2008. Reaction of drought-tolerant soybean genotypes to Macrophomina phaseolina. Plant Health Prog. 9. doi:10.1094/PHP-20080618-01-RS.

Wrather, J. A., Shannon, J. G., and Mengistu, A. 2007. Impact of soybean planting date on soil population density of Macrophomina phaseolina. Plant Health Prog. 8. doi: 10.1094/PHP-2007-0917-03-RS.

Wyllie, T. D. 1988. Charcoal rot of soybean current status. Pages 103-106 in: Soybean Diseases of the North Central Region. T. D. Wyllie and D. H. Scott, eds. American Phytopathological Society, St. Paul MN.

Young, P. A. 1949. Charcoal Rot of Plants in East Texas. Texas Agricultural Experiment Station, College Station, TX. 